An overview of the surgery of hydrocephalus: past, present and future, by Hirsch JF, Hopital Necker Enfants Malades, Paris, France is published in Acta Neurochir (Wien) 1992; 116:155-160. The need for research in the causes and prevention of hydrocephalus is stressed.

\title{
NEONATAL CEREBRAL VENOUS THROMBOSIS
}

The clinical presentation and management of 7 neonates with idiopathic cerebral venous thrombosis (CVT) are reported from the Floating Hospital for Infants and Children, New England Medical Center Hospitals, Tufts University School of Medicine, Boston, MA. Unexplained seizures in 3 infants and unexplained lethargy in 4 led to neurological evaluation and the diagnosis of CVT. Follow-up neurological evaluation through 6 months of age showed normal development. Conventional magnetic resonance images indicated more extensive thrombosis than was suggested by cranial CT. MR phase imaging confirmed thrombosis and established absence of blood flow in cerebral veins or sinuses. No infant received treatment with anticoagulants. (Rivkin MJ et al. Neonatal idiopathic cerebral venous thrombosis: an unrecognized cause of transient seizures or lethargy. Ann Neurol July 1992; 32:51-56.) (Correspondence: Dr. Rivkin, New England Medical Center Hospitals, Box 330, Division of Pediatric Neurology, 750 Washington St., Boston, MA 02111.)

COMMENT. Cerebral venous thrombosis may explain transient neonatal seizures or lethargy in newborn infants and may be diagnosed by MR and MR phase imaging.

\section{METABOLIC DISORDERS}

\section{HYDROXYGLUTARIC ACIDEMIA}

Increased urinary excretion of L-2-hydroxyglutaric acid, found in 8 mentally retarded patients from 5 unrelated families including 3 pairs of siblings seen in various centers in Europe, was reported from University Hospital Amsterdam, the Netherlands. The first symptoms occurred between 1 and 5 years of age and consisted of abnormal gait. Febrile seizures occurred in 7 of 8 patients. Cerebellar dysfunction was the principle neurological abnormality in later childhood and adulthood. MRI revealed subcortical leukoencephalopathy, cerebellar atrophy, and changes in the putamina and dentate nuclei. L-2-hydroxyglutaric acid was also increased in the CSF and plasma. Lysine was increased in CSF and plasma and glutaric acid was increased in the plasma of 2 patients. Loading and dietary studies failed to reveal the origin of the L-2-hydroxyglutaric acid. (Barth PG et al. L-2-Hydroxyglutaric acidemia: a novel inherited neurometabolic disease. Ann Neurol July 1992; $\underline{32}: 66-71$.)

COMMENT. Glutaric acidemia, an autosomal recessively inherited disease caused by deficiency of glutaryl-Coenzyme A dehydrogenase, was manifested by acute dystonia in 3 infants reported from the Children's Hospital of Pittsburgh, PA (See Ped Neurol Briefs Jan 
1989). Dystonia was also reported in 3 of the 8 patients with L-2hydroxyglutaric acidemia.

\section{MUCOPOLYSACCHARIDOSIS: MRI STUDY}

Characteristic changes in the MRI of 2 brothers with mucopolysaccharidosis type I are reported from the Departments of Paediatrics, Neuroradiology and Neurology, University of Ancona, Italy. One patient was mentally retarded and the other had a normal IQ. The MRI showed a honeycomb-like appearance of the thalami, hypoplasia of the cerebellum and an enlarged ventricular system, with changes in the white matter behind the occipital horns. These changes were not correlated with the mental retardation. (Gabrielli O et al. Cerebral MRI in two brothers with mucopolysaccharidosis type I and different clinical phenotypes. Neuroradiology Aug 1992; 34:313-315.) (Correspondence: Dr. O. Gabrielli, Department of Pediatrics, University of Ancona, Via F. Corridoni 11, I-60123 Ancona, Italy.)

COMMENT. Glycosaminoglycans and glycolipids accumulate in the cells of the central nervous system in mucopolysaccharidosis type I. It is suggested that the mental retardation could be tied to neuronal damage caused by lysosomal storage of these substances. The cell biology of glycosaminoglycans in regulating normal cerebrospinal fluid absorption is reviewed by Knepper PA and McLone DG, Children's Memorial Hospital and Northwestern University Medical School, Chicago, (Pediat Neurol Sci 1986; 12:240-251).

\section{METABOLIC ALTERATIONS IN MULTIPLE SCLEROSIS}

Alterations in regional cerebral metabolism have been demonstrated by in vivo proton magnetic resonance spectroscopy of 8 children ( 7 - 16 years) with established multiple sclerosis at the Max-Planck-Institut fur biophysikalische Chemie, Postfach, and Abt. Kinderheilkunde, Schwerpunkr Neuropadiatrie, Georg-August-Universitat, Gottingen, Federal Republic of Germany. MS plaques showed a decrease in $\mathrm{N}$-acetylaspartate and creatines, and an increase in cholines and myo-inositol. Cortical gray matter related to MS lesions showed a reduction of $\mathrm{N}$-acetylaspartate. Functional impairment in MS was linked to gross metabolic disturbances of neuronal cell chemistry. (Bruhn $\mathrm{H}$ et al. Multiple sclerosis in children: cerebral metabolic alterations monitored by localized proton magnetic resonance spectroscopy in vivo. Ann Neurol Aug 1992; 32:140-150.) (Correspondence: Dr. Bruhn, Max-Planck-Institut fur biophysikalische Chemie, Postfach 2841, D-3400 Gottingen, Federal Republic of Germany.)

COMMENT. Proton magnetic resonance spectroscopy has revealed metabolic alterations associated with multiple sclerosis in focal lesions and in the adjacent cortex. The method could aid in the differentiation of MS plaques from other disorders and in monitoring response to therapy. For additional articles on MS in children see Progress in Pediatric Neurology, Millichap JG, 1991, 507-510. 